\title{
KEANEKARAGAMAN DAN KELIMPAHAN MAKROZOOBENTHOS PADA EKOSISTEM MANGROVE DESA DARUBA PANTAI KABUPATEN PULAU MOROTAI
}

\author{
Djainudin Alwi, Sandra Hi. Muhammad, Henderson Herat \\ Program Studi IImu Kelautan, Fakultas Perikanan dan IImu Kelautan, \\ Universitas Pasifik Morotai, Maluku Utara, Indonesia \\ E-mail : djainudinalwi@gmail.com
}

Received February 2020, Accepted April 2020

\begin{abstract}
ABSTRAK
Ekosistem mangrove berperan sebagai habitat berbagai jenis satwa, salah satunya yaitu makrozoobenthos. Makrozoobenthos berperan sebagai konsumen primer dan ada pula yang berperan sebagai konsumen sekunder atau konsumen yang menempati tempat yang lebih tinggi. Pada umumnya, Makrozoobenthos merupakan makanan alami bagi berbagai satwa perairan yang berukuran besar. Penelitian ini bertujuan menganalisis kelimpahan makrozoobenthos dan menganalisis struktur komunitas makrozoobenthos di kawasan ekosistem mangrove Daruba Pantai. Penelitian ini dilaksanakan pada bulan November sampai Desember 2019 yang berlokasi di kawasan Mangrove Desa Daruba Pantai. Pengambilan data menggunakan metode sampel kuadrat (Quadrat Sampling) dengan ukuran plot $1 \times 1 \mathrm{~m}^{2}$. Metode analisis data menggunakan analisis indeks ekologi seperti kelimpahan individu, kelimpahan relatif, keanekaragaman jenis, keseragaman dan dominasi. Hasil penelitian menunjukan kelimpahan individu makrozoobenthos tertinggi berada pada stasiun ke I yaitu 33,333 (Ind/ $\mathrm{m}^{2}$ ) dan terendah berada di stasiun I dan II yaitu Polymesoda bengalensis 1,111 $\left(\mathrm{Ind} / \mathrm{m}^{2}\right)$. Sedangkan Kelimpahan Relatif tertinggi ada di stasiun II yaitu Episesarma (0,200\%) dan terendah ada di stasiun I dan II yaitu Polymesoda bengalensis (0,007\%). Hasil analisis indeks ekologi Keanekragaman $\left(\mathrm{H}^{\prime}\right)$ stasiun I yaitu $(2,146)$, stasiun II $(2,158)$ dan stasiun III $(2,131)$ termasuk dalam kategori sedang. Indeks Keseragaman (E) pada stasiun I berkisar $(0,895)$, stasiun II $(0,900)$, sedangkan pada stasiun III $(0,925)$ termasuk dalam kategori tinggi. Indeks Dominasi pada stasiun I yaitu $(0,132)$, stasiun II $(0,132)$ dan pada stasiun III yaitu $(0,130)$ termasuk dalam kategori rendah.
\end{abstract}

Kata Kunci :Keanekaragaman, Kelimpahan, Makrozoobenthos, Mangrove, Daruba Pantai.

\section{ABSTRACT}

THE DIVERSITY AND ABUNDANCE OF MACROZOOBENTHOS IN MANGROVE ECOSYSTEMS AT DARUBA VILLAGE COASTAL PULAU MOROTAI REGENCY. Mangrove ecosystems play a role as a habitat for 
various species of animals, one of which is macrozoobenthos. Macrozoobenthos acts as the primary consumer and some have a role as secondary consumers or consumers who occupy a higher place. In general, Macrozoobenthos is a natural food for a variety of large aquatic animals. This research aims to analyze the abundance of macrozoobenthos and analyze the structure of the macrozoos community in the area of the Daruba Coastal mangrove ecosystem. This research was conducted from November to December 2019 located in the Mangrove area of Daruba Pantai Village. Retrieval of data using the method of quadratic sampling (Quadrat Sampling) with a plot size of $1 \times 1$ $m^{2}$. Data analysis methods use ecological index analysis such as individual abundance, relative abundance, species diversity, uniformity, and dominance. The results showed the highest abundance of macrozoobenthos individuals were at a station I which was 33,333 (Ind / $\mathrm{m}^{2}$ ) and the lowest was at stations I and II namely Polymesoda bengalensis 1.111 (Ind / $\mathrm{m}^{2}$ ). While the highest relative abundance in at station II, Episesarma (0.200\%) and the lowest are at a station I and II, Polymesoda bengalensis (0.007\%). The results of the analysis of the Ecological diversity index $\left(H{ }^{\prime}\right)$ of Station I, namely $(2,146)$, Station II $(2,158)$ and Station III $(2,131)$ are included in the medium category. The Uniformity Index (E) at a station I ranges (0.895), station II (0.900), while at station III (0.925) is included in the high category. The Domination Index at a station I (0.132), station II (0.132) and at station III (0.130) are in a low category.

Keywords : Diversity, Abundance, Macrozoobenthos, Mangroves, Daruba village.

\section{PENDAHULUAN}

Ekosistem mangrove (bakau) adalah ekosistem yang berada di daerah tepi pantai yang dipengaruhi oleh pasang surut air laut sehingga selalu tergenang air. Ekosistem mangrove berada di antara level pasang naik tertinggi sampai level di sekitar atau di atas permukaan laut rata-rata pada daerah pantai yang terlindungi (Supriharyono, 2009). Ekosistem mangrove berperan penting dalam pengembangan perikanan pantai, karena merupakan tempat berkembang biak, memijah, dan sebagai tempat pembesaran bagi beberapa jenis ikan, kerang, kepiting, dan udang (Kariada dan Andin, 2014).

Makrozoobenthos merupakan kelompok benthos yang memiliki ukuran lebih dari $1 \mathrm{~mm}$ dan pertumbuhan dewasanya memiliki ukuran 3-5 mm (Vernberg, 1981 dalam Fachrul, 2007). Makrozoobenthos membantu mempercepat proses dekomposisi materi organik. Hewan bentos, terutama herbivore dan detritor, dapat menghancurkan makrofit akuatik dan serasah yang masuk kedalam perairan menjadi potongan-potongan kecil, sehingga mempermudah mikroba untuk menguraikan menjadi nutrien bagi produsen perairan dalam rantai makanan. Berbagai jenis makrozoobenthos adapula berperan sebagai konsumen primer dan ada 
pula yang berperan sebagai konsumen sekunder atau konsumen yang menempati tempat yang lebih tinggi. Pada umumnya, Makrozoobenthos merupakan makanan alami bagi ikan-ikan didasar (bottom feeder) (Arief, 2003).

Makrozoobenthos hidup menempel, melata (sesile), meliang dan membenamkan diri baik di dasar perairan maupun di permukaan dasar perairan. Makrozoobenthos yang hidup menetap dikawasan mangrove kebanyakan hidup pada substrat keras sampai berlumpur (Arief, 2003). Hewan ini memegang beberapa peran penting dalam perairan seperti dalam proses dekomposisi dan mineralisasi material organik yang memasuki perairan, serta menduduki beberapa tingkatan trofik dalam rantai makanan. Makrozoobenthos yang umum ditemui di kawasan mangrove adalah dari Kelas Crustacea, Polychaeta, Bivalvia dan Kelas Gastropoda.

Perairan Desa Daruba Pantai merupakan perairan yang memiliki banyak potensi sumber daya hayati laut khususnya di ekosistem mangrove, namun sampai saat ini belum dimanfaatkan secara optimal termasuk makrozoobenthos. Selain itu belum ada data dan informasi mengenai makrozoobentos penghuni ekosistem mangrove. Penelitian mengenai struktur komunitas mangrove dilokasi yang sama sudah dilakukan oleh Alwi, et al (2019), akan tetapi penelitian mengenai biota asosiasi mangrove sampai saat belum dilakukan. Olehnya itu, perlu adanya kajian mengenai aspek ekologi dari makrozoobentos penghuni ekosistem mangrove di Desa Daruba Pantai Kabupaten Pulau Morotai, sehingga dapat diperoleh informasi dan sekaligus sebagai data base dalam pengelolaan secara berkelanjutan.

\section{MATERI DAN METODE}

\section{Waktu dan Tempat Penelitian}

Penelitian ini dilaksanakan pada bulan November-Desember 2019. Berlokasi di kawasan mangrove Desa Daruba Pantai, Kabupaten Pulau Morotai. Berikut peta lokasi penelitian (Gambar 1).

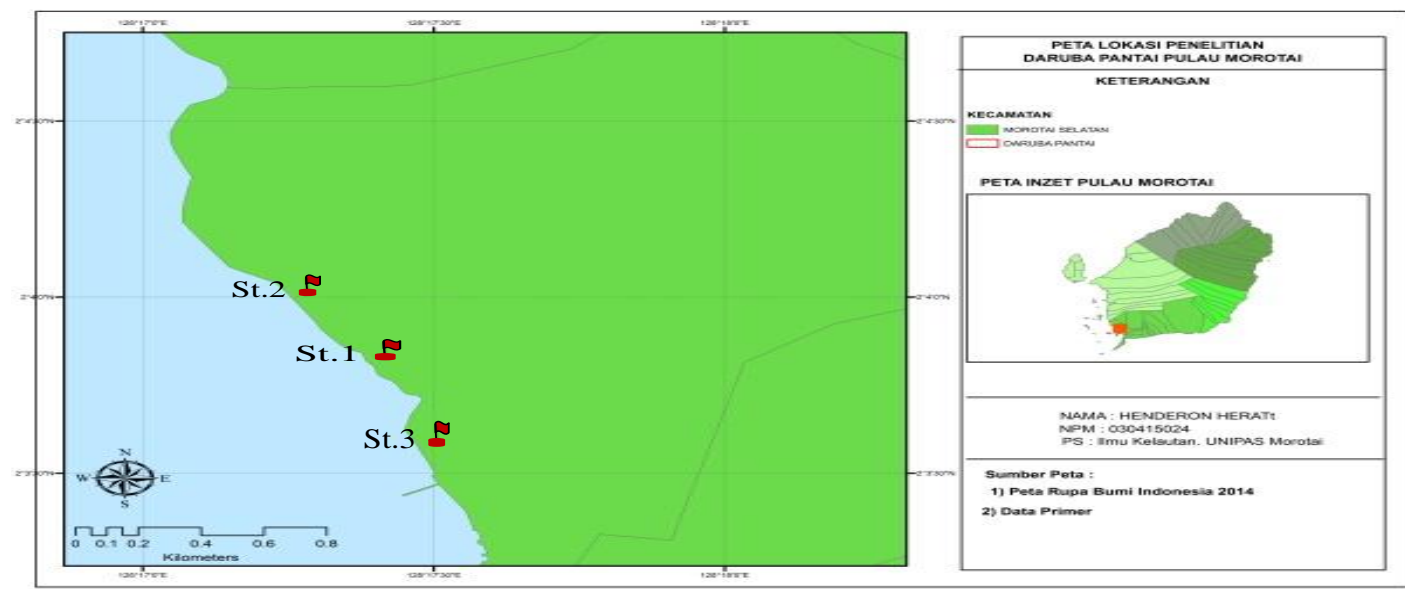

Gambar 1. Peta Lokasi Penelitian 


\section{Teknik Pengumpulan Data}

Teknik pengumpulan data dengan cara pengamatan langsung terhadap objek penelitian. Data primer mencakup pengamatan dan pengukuran terhadap objek penelitian berupa jenis dan jumlah individu organisme makrozoobenthos di ekosistem mangrove. Sedangkan data sekunder diperoleh berdasarkan studi kepustakaan tentang jenis-jenis makrozoobenthos dan parameter lingkungan yang berpengaruh dalam penelitian ini.

Stasiun dan Plot penelitian ditentukan dilokasi secara konseptual berdasarkan keterwakilan lokasi kajian. Posisi stasiun ditarik dari garis pantai secara tegak lurus menuju daratan melalui zonasi ekosistem mangrove. Jarak antara satu stasiun dengan stasiun lainnya adalah $50 \mathrm{~m}$ dan penarikan tali transek sejauh $50 \mathrm{~m}$ meter berdasarkan keterwakilan lokasi sehingga ditetapkan sebanyak tiga stasiun pengamatan, Plot dengan ukuran $1 \times 1 \mathrm{~m}^{2}$ ditetapkan pada setiap transek, dimana setiap transek terdapat 3 plot, jarak antar plot 10 meter. (Gambar 2)

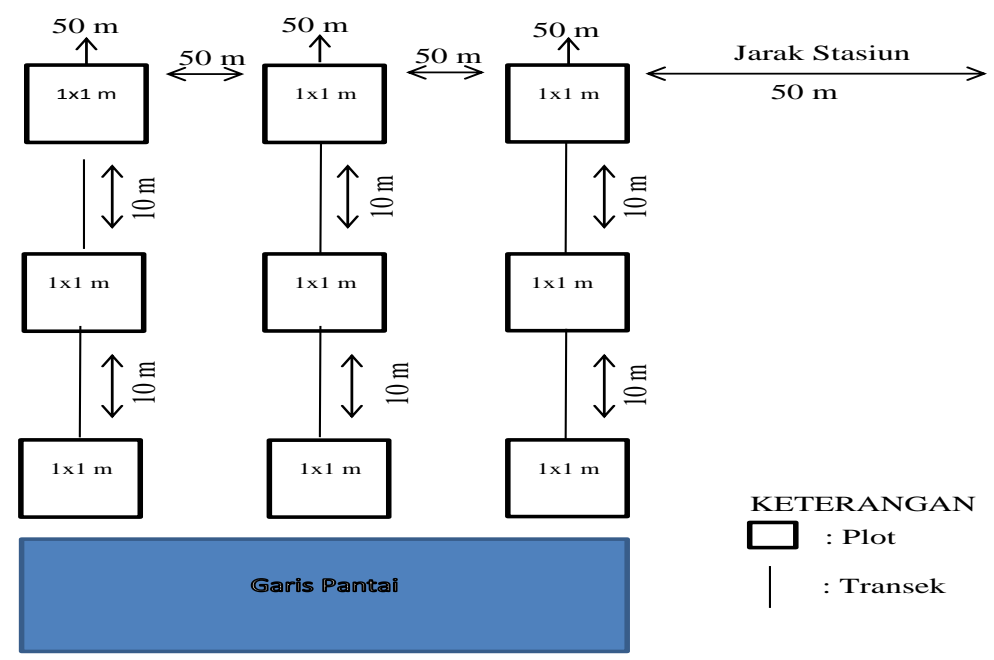

Gambar 2. Skema Pengambilan Data

\section{Analisis Data}

Analisis data kelimpahan dan struktur komunitas makrozoobenthos yang ditemukan dilokasi penelitian menggunakan formula sebagai berikut:

1. Kelimpahan Individu

Kelimpahan individu Makrozoobenthos dihitung dengan menggunakan indeks Shannon-Winner (Odum, 1971)

Dimana :

$$
\mathrm{Y}=\frac{10.000 \times a}{b}
$$

$\mathrm{Y}=$ Jumlah Organisme Makrozoobentos (ind $/ \mathrm{m}^{2}$ )

$\mathrm{a}=$ Jumlah individu jenis Makrozoobenthos (ind)

$\mathrm{b}=$ Luas Kuadrat $\left(\mathrm{m}^{2}\right)$ 
2. Kelimpahan Relatif

Kelimpahan Relatif individu Makrozoobenthos dihitung dengan menggunakan rumus Cox (1967) dalam Effendy (1993)

Dimana :

$$
\mathrm{R}=\frac{n i}{N} x 100 \%
$$

$$
\begin{aligned}
& R=\text { Kelimpahan Relatif } \\
& n i=\text { Jumlah Individu Setiap Jenis } \\
& N=\text { Jumlah Seluruh Individu }
\end{aligned}
$$

3. Indeks Keanekaragaman (H')

Untuk menghitung indeks keanekargaman $\left(\mathrm{H}^{\prime}\right)$ jenis dihitung menurut Shannon-Winner dalam Krebs (1994), sebagai berikut :

Dimana :

$$
H^{\prime}=-\sum\left(\frac{n i}{N}\right) \times \operatorname{In}\left(\frac{n i}{N}\right)
$$

$$
\begin{aligned}
& \mathrm{H}^{\prime}=\text { Indeks Keanekaragaman } \\
& n i=\text { Jumlah Individu setiap Jenis } \\
& \mathrm{N}=\text { Jumlah Individu seluruh Jenis }
\end{aligned}
$$

Indeks keanekaragaman $\left(\mathrm{H}^{\prime}\right)$ terdiri dari beberapa kriteria, yaitu:

$\mathrm{H}^{\prime}>3,0=$ Menunjukan keanekaragaman sangat tinggi

$\mathrm{H}^{\prime}$ 1,6-3,0 = Menunjukan keanekaragaman tinggi

$\mathrm{H}^{\prime} 1,0-1,5=$ Menunjukan keanekaragaman sedang

$\mathrm{H}^{\prime}<1=$ Menunjukan keanekaraaman rendah

4. Indeks Keseragaman (E)

Sedangkan untuk menghitung Indeks Keseragaman (E) jenis dapat menggunakan rumus. Evennex Indeks dari Shannon Indeks of Diversity sebagai berikut :

Dimana :

$$
E=\frac{H^{\prime}}{\operatorname{LnS}}
$$

$$
\begin{aligned}
& E=\text { Indeks Keseragaman } \\
& H^{\prime}=\text { Indeks Keanekaragaman } \\
& \mathrm{S}=\text { Jumlah spesies }
\end{aligned}
$$

Nilai indeks keseragaman dikelompokan dalam tiga kriteria, yaitu:

$$
\begin{array}{ll}
\mathrm{E}<0,4 & =\text { Tingkat keseragaman populasi kecil } \\
0,4<\mathrm{E}<0,6 & =\text { Tingkat keseragaman poppulasi sedang } \\
\mathrm{E}>0,6 & =\text { Tingkat keseragaman populasi besar }
\end{array}
$$

\section{Indeks Dominansi (C)}

Indeks dominansi dihitung dengan menggunakan rumus Indeks Of Dominance dari Simpson (Odum, 1971). Sebagai berikut :

$$
C=\sum\left(\frac{n i}{N}\right)^{2}
$$




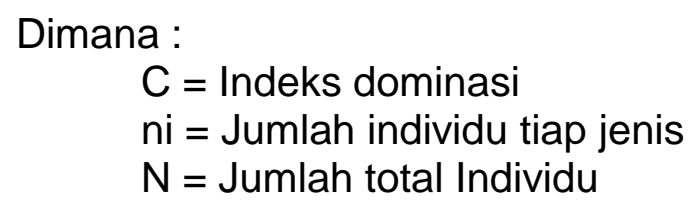

Nilai indeks dominasi dikelompokan dalam tiga kriteria, yaitu:

$0<\mathrm{C} \leq 0,5=$ Dominasi rendah

$0,5<\mathrm{C} \leq 0,7=$ Dominasi sedang

$0,7<\mathrm{C} \leq 1=$ Dominasi tinggi

\section{HASIL DAN PEMBAHASAN}

\section{Jenis Makrozoobenthhos yang ditemukan}

Berdasarkan hasil penelitian yang dilakukan pada ekosistem mangrove di Daruba Pantai, Kabupaten Pulau Morotai, teridentifikasi sebanyak 11 jenis makrozoobenthos yang tersebar pada tiga stasiun. Terdiri dari 7 jenis dari kelas Gastropoda, 1 jenis dari Bilvavia dan 3 jenis dari kelas Crustacea. Adapun jenis makrozooobenthoos yang ditemukan dapat dilihat pada tabel berikut :

Tabel 1. Jenis makrozobenthos yang ditemukan di lokasi penelitian

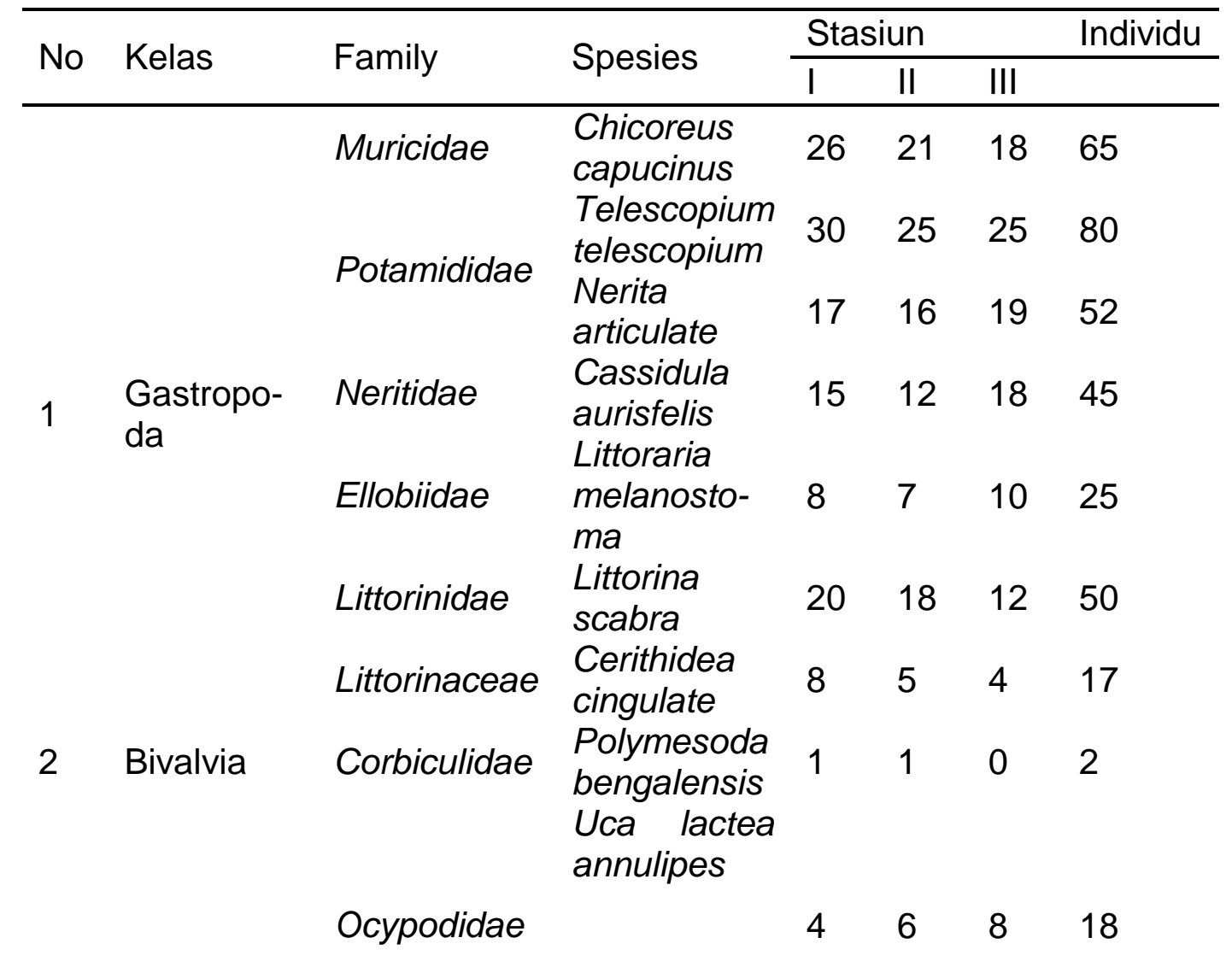




\begin{tabular}{|c|c|c|c|c|c|c|c|}
\hline \multirow{2}{*}{ No } & \multirow{2}{*}{ Kelas } & \multirow{2}{*}{ Family } & \multirow{2}{*}{ Spesies } & \multicolumn{3}{|c|}{ Stasiun } & \multirow[t]{2}{*}{ Individu } \\
\hline & & & & 1 & II & III & \\
\hline \multirow[t]{3}{*}{3} & Crustacea & Portunidae & $\begin{array}{l}\text { Scylla } \\
\text { serrata }\end{array}$ & 3 & 5 & 2 & 10 \\
\hline & & Sesarmidea & Episesarma & 19 & 29 & 25 & 73 \\
\hline & & & $\begin{array}{l}\text { Jumlah } \\
\text { Total } \\
\text { Individu }\end{array}$ & $\begin{array}{l}15 \\
1\end{array}$ & $\begin{array}{l}14 \\
5\end{array}$ & $\begin{array}{l}14 \\
1\end{array}$ & 437 \\
\hline
\end{tabular}

\section{Kelimpahan Individu}

Hasil analisis kelimpahan makrozoobnthos pada stasiun I tertinggi terdapat pada spesies Telescopium telescopium dengan nilai kelimpahan individu sebanyak 33,333 Ind/ $\mathrm{m}^{2}$, kemudian Chicoreus capucinus dengan nilai $28,889\left(\mathrm{Ind} / \mathrm{m}^{2}\right)$. Sedangkan kelimpahan yang paling terendah adalah spesies Polymesoda bengalensis dengan nilai $1,111 \mathrm{Ind} / \mathrm{m}^{2}$ (Gambar 3 ).

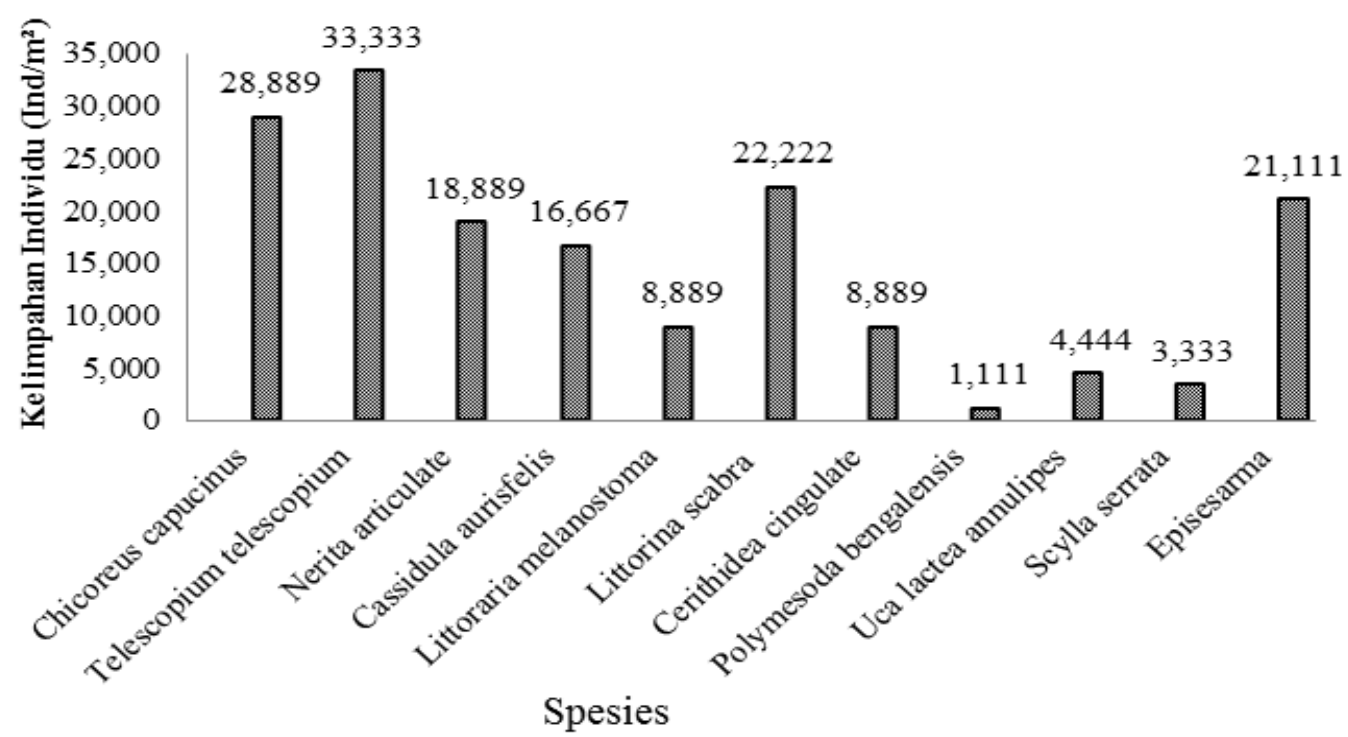

Gambar 3. Grafik kelimpahan individu stasiun I

Kemudian hasil analisis kelimpahan individu pada stasiun II dengan nilai tertinggi adalah spesies Episesarma yaitu $32,222 \mathrm{Ind} / \mathrm{m}^{2}$, dan kelimpahan terendah spesies Polymesoda bengalensis dengan nilai $1,111 \mathrm{lnd} / \mathrm{m}^{2}$ (Gambar 4). 


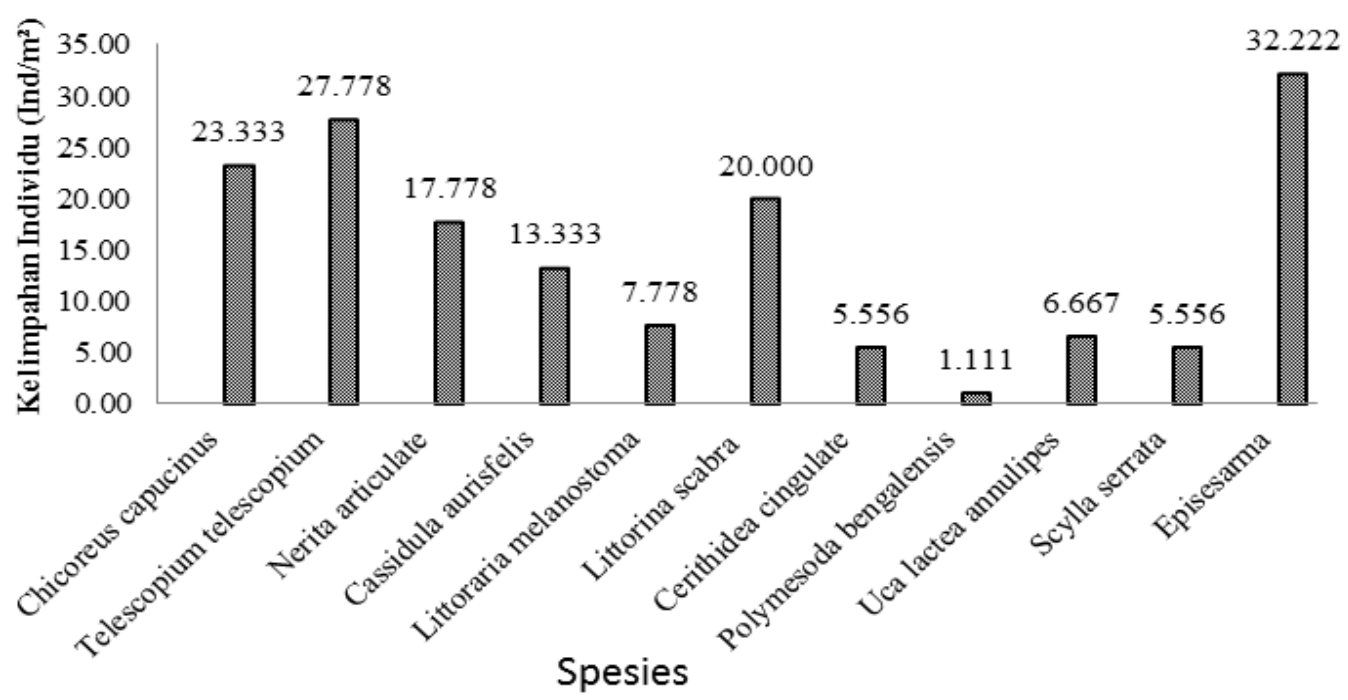

Gambar 4. Grafik kelimpahan individu stasiun II

Kelimpahan individu pada stasiun III dengan nilai tertinggi terdapat spesies Telescopiun telescopium dan Episesarma dengan nilai yang sama yaitu $27,778 \mathrm{Ind} / \mathrm{m}^{2}$, sedangkan nilai yang paling terendah adalah spesies Scylla serrata dengan nilai 2,222 Ind//2 (Gambar 5).

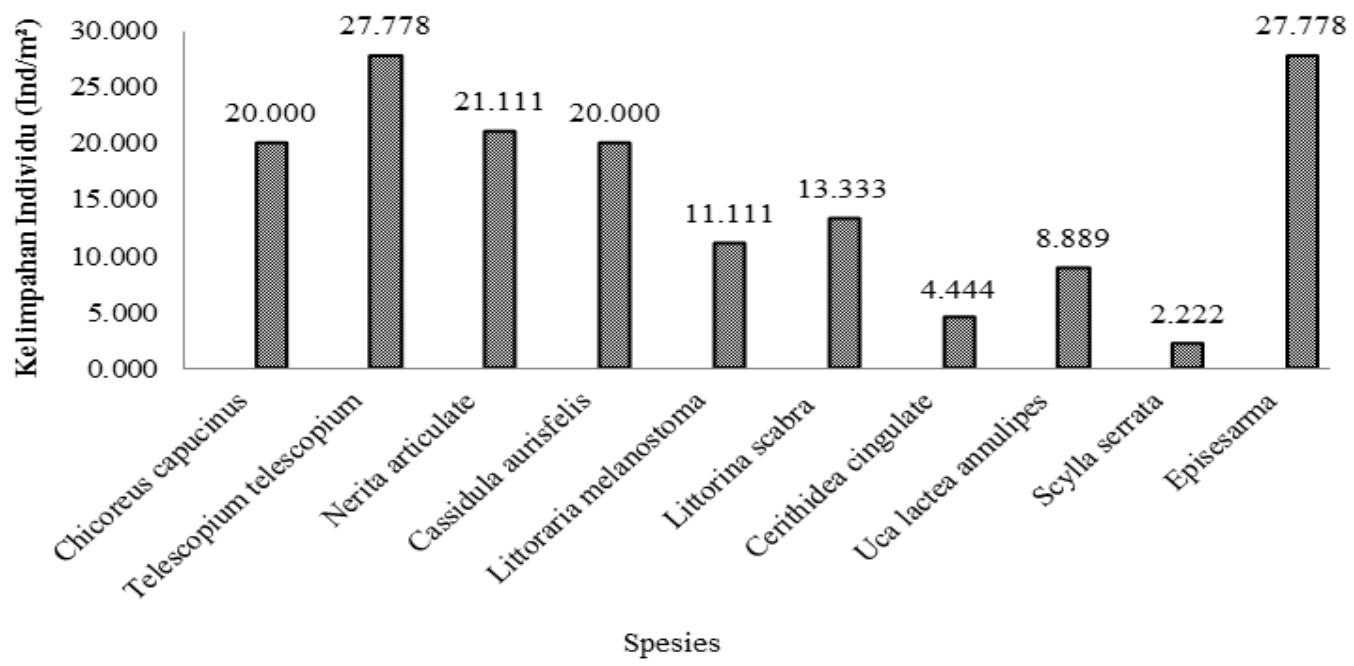

Gambar 5. Grafik kelimpahan individu stasiun III

\section{Kelimpahan Relatif}

Analisis kelimpahan relatif pada stasiun I nilai tertinggi yang didapat adalah spesies Telescopium telescopium yaitu $0,198 \%$, dan kemudian disusul dengan nilai yang hampir sama yaitu spesies Chicoreus capucinus 
0,172 \%. Sedangkan dengan nilai yang terendah adalah spesies Polymesoda bengalensis 0,007\% (Gambar 6).

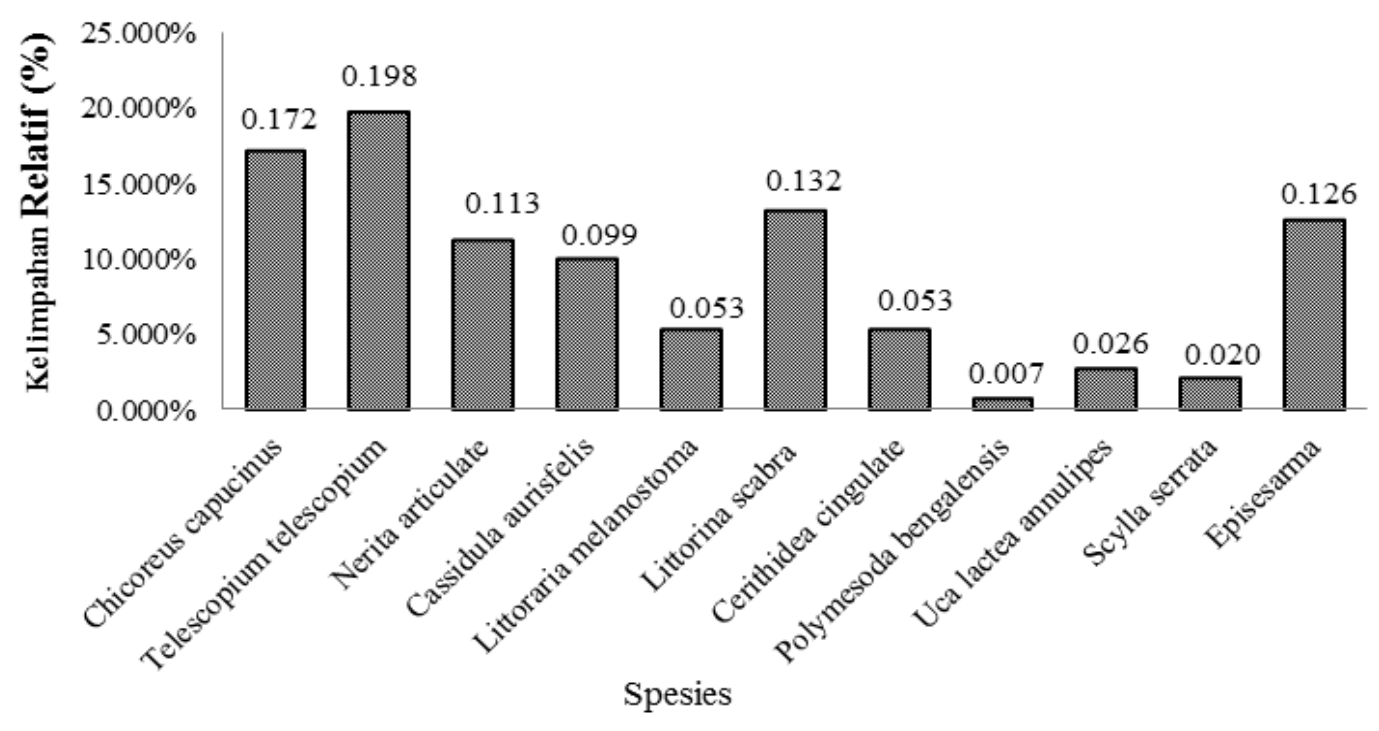

Gambar 6. Grafik kelimpahan relatif stasiun I

Hasil analisis kelimpahan relatif pada stasiun II dengan nilai tertinggi yaitu spesies Episesarma sebesar 0,200\%, sedangkan untuk nilai yang paling rendah ditemukan adalah spesies Polymesoda bengalensis 0,007\% (Gambar 7).

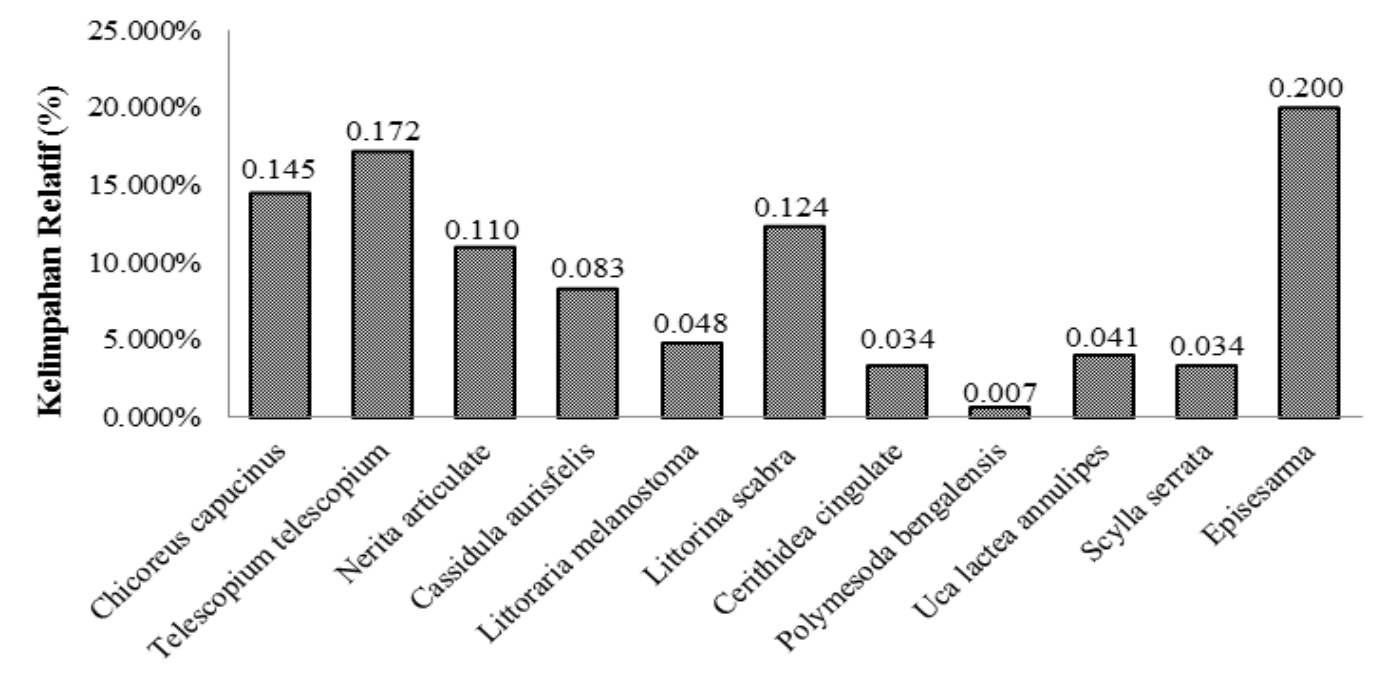

Gambar 7. Grafik kelimpahan relatif stasiun II

Kelimpahan relatif pada stasiun III ini yang temukan adalah 2 spesies Telescopium telescopium dan Episesarma dengan nilai 
persentase yang sama yaitu $0,177 \%$. Sedangkan yang paling terendah ditemukan adalah spesies Scylla serrata yaitu 0,014 \% (Gambar 8).

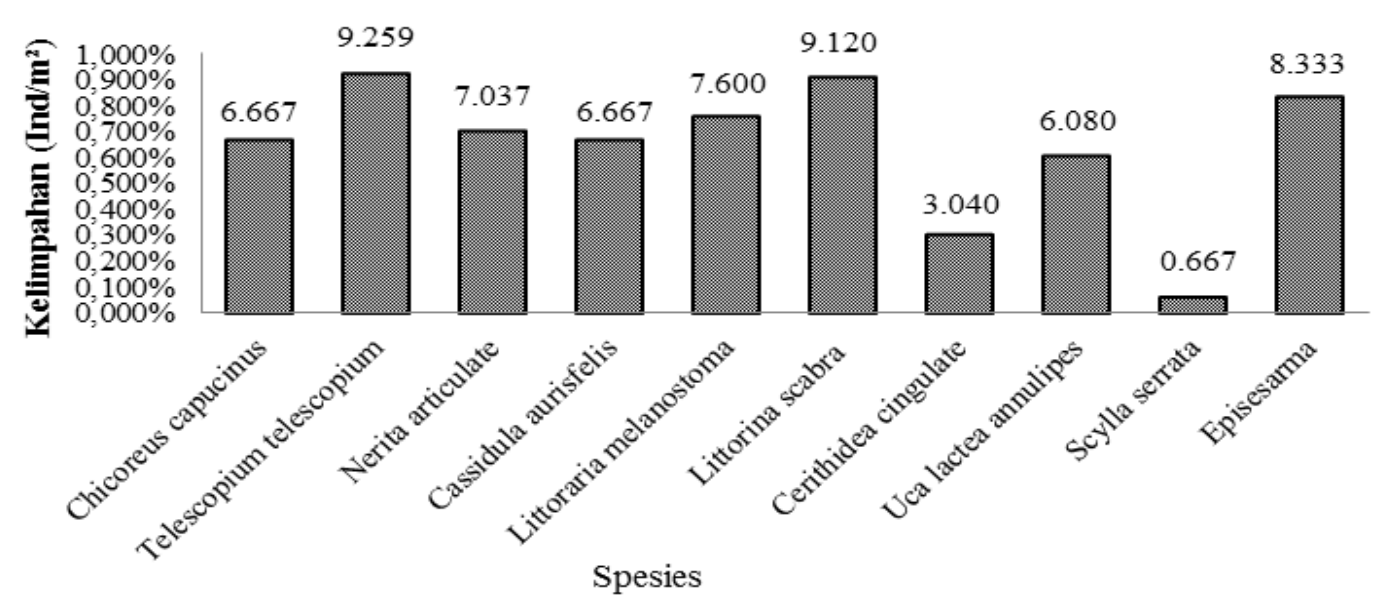

Gambar 8. Grafik kelimpahan relatif stasiun III

Hasil pengamatan makrozoobenthos yang ditemukan pada semua stasiun terlihat bervariasi, baik kelimpahan individu maupun kelimpahan relatifnya. Kelas gastropoda merupakan makrozoobenthos yang paling tinggi nilai kelimpahannya. Hal ini ini disebabkan karena gastropoda memiliki adaptasi yang cukup kuat terhadap perubahan lingkungan karena memiliki cangkang yang keras dan mempunyai sifat mobile yang lebih aktif memungkinkan untuk bertahan hidup dibandingkan dengan kelas yang lain. Nybakken, (1988) bahwa gastropoda mempunyai operkulum yang menutup rapat celah cangkang. Ketika pasang turun mereka masuk kedalam cangkang lalu menutup celah menggunakan operkulum sehingga kekurangan air dapat diatasi.

Barnes (1987), mengatakan bahwa kelas Gastropoda mempunyai anggota terbanyak dan merupakan moluska yang paling sukses karena mempunyai jenis habitat yang bervariasi. Selain itu, Gastropoda memiliki pola adaptasi yang cukup besar dengan perubahan faktor lingkungan yang disebabkan oleh pasang surut. Sementara nilai tertinggi kedua yang ditemukan pada semua stasiun pengamatan berasal dari kelas Crustacea spesies Episesarma, karena spesies ini sangatlah bersifat predator dan deposit feeder yang menyukai substrat pasir dan berlumpur (Smaldon, 1979).

Kelas Bivalvia spesies Polymesoda bengalensis dan kelas Crustacea spesies Scylla serrata merupakan makrozoobenthos dengan nilai kelimpahan terendah. Hal ini disebabkan karena spesies tersebut merupakan organisme peliang pasir yang dalam sehingga sulit untuk ditemukan dalam jumlah banyak. Hasil penelitian Widyastuti, (2011) melaporkan hal yang sama, bahwa hewan-hewan peliang seperti spesies Polymesoda bengalensis dan Scylla serrata paling rendahnya 
kelimpahannya, disebabkan karena jenis kepiting ini banyak membuat lubang yang cukup dalam dan kemungkinan lain dapat disebabkan pada saat pengamatan, organisme terlebih dahulu meninggalkan tempat saat mendapat gangguan dari lingkungan sekitar, karena hewan ini adalah bergerak cepat serta mudah berpindah dari daerah permukaann yang terbuka ke dalam celah-celah lubang atau galian yang sangat basah, sehingga jarang ditemukan di daerah ekosistem mangrove. Kondisi habitat yang lebih kering dengan suhu dan salinitas tinggi dan kurangnya vegetasi mangrove menyebabkan sedikitnya jenis kepiting yang mampu beradaptasi. Ravichandran et al, (2011) melaporkan bahwa daerah mangrove di sekitar daratan yang kering dan berada di atas garis pasang tertinggi memiliki kelimpahan jenis kepiting yang rendah.

\section{Struktur Komunitas Makrozoobenthos}

Hasil analisis struktur komunitas makrozoobenthos yang ditemukan pada lokasi penelitian disajikan pada tabel 2 berikut ini :

Tabel 2. Struktur Komunitas Makrozoobenthos pada Ekosistem Mangrove

\begin{tabular}{lllllll}
\hline \multicolumn{7}{l}{ Struktur komunitas makrozoobenthos } \\
\hline Stasiun & $\mathrm{H}^{\prime}$ & Kategori & $\mathrm{E}$ & Kategori & $\mathrm{C}$ & Kategori \\
\hline I & 2.146 & Sedang & 0.895 & Tinggi & 0.132 & Rendah \\
II & 2.158 & Sedang & 0.900 & Tinggi & 0.132 & Rendah \\
III & 2.131 & Sedang & 0.925 & Tinggi & 0.130 & Rendah \\
\hline
\end{tabular}

Tabel 2 menunjukan bahwa nilai $H^{\prime}$ pada stasiun I sebesar 2,146, stasiun II 2,158, sedangkan pada stasiun III 2,131. Secara umim nilai indeks keanekaragaman dilokasi penelitian termasuk kategori sedang. Keanekaragaman yang sedang menunjukan penyebaran jumlah individu tiap jenis yang sedang dan kestabilan juga sedang. Menurut Hardjosuwarno (1990) menyatakan bahwa indeks keanekaragaman $\left(\mathrm{H}^{\prime}\right)$ terdiri dari beberapa kriteria yaitu : jika $\left(\mathrm{H}^{\prime}\right)$ lebih dari 3,0 menunjukkan keanekaragaman sangat tinggi, jika nilai $\left(H^{\prime}\right)$ sebesar 1,0-1,5 menunjukan keanekaragaman sedang. Hal ini sebagaimana pernyataan Soegianto (1994), suatu komunitas dikatakan mempunyai keanakeragaman jenis tinggi jika komunitas itu disusun banyak jenis dengan kelimpahan jenis yang sama atau hampir sama, sebaliknya jika komunitas itu disusun oleh sedikit jenis dan jika hanya sedikit jenis yang mendominasi maka keanekaragaman jenisnya rendah.

Indeks keseragaman (E) pada stasiun I berkisar 0,895, stasiun II 0,900 , sedangkan pada stasiun III 0,925. Hal ini menunjukan bahwa nilai indeks keseragaman stabil karena keseragaman pada ketiga stasiun mendekati 0. Menurut Odum (1993) jika nilai indeks keseragaman (E) berkisar $0,75<\mathrm{E}<1,00$. Bila nilai mendekati 0 berarti keseragaman stabil karena adanya jenis yang mendominasi, dan bila mendekati 1 keseragaman stabil yang menunjukan tidak ada jenis yang mendominasi. 
Dominasi dikatakan tinggi jika $\mathrm{C}=1$, sedangkan pada tabel 2 terlihat nilai indeks dominasi pada stasiun I yaitu 0,132 , stasiun II 0,132 , dan pada stasiun III yaitu 0,130 . Terlihat dari nilai indeks dominasi pada tabel 2 diatas, menunjukan bahwa dominasi dinyatakan rendah. Nilai indeks dominasi mempunyai kecenderungan mendekati 0 , artinya tidak ada jenis yang mendominasi suatu perairan yang berarti setiap individu pada stasiun pengamatan mempunyai kesempatan yang sama dan secara maksimal dalam memanfaatkan sumber daya yang ada didalam perairan tersebut. Hal ini sesuai dengan pernyataan Odum, (1993) bahwa nilai indeks dominansi yang tinggi menyatakan konsentrasi dominansi yang tinggi (ada individu yang mendominansi), sebaliknya nilai indeks dominansi yang rendah menyatakan konsentrasi yang rendah (tidak ada yang dominan).

Tinggi rendahnya keanekaragaman, keseragaman dan dominasi pada setiap stasiun pengamatan disebabkan oleh parameter fisika kimia dan biologi yaitu suhu, salinitas, $\mathrm{pH}$, oksigen terlarut maupun tingkah laku suatu organisme yang mampu menyesuai diri pada kondisi lingkungan tersebut. Yulianto (2006), menyatakan bahwa keadaan habitat yang berubah-ubah dapat berpengaruh terhadap kemerataan jenis yang hidup pada habitat tersebut.

\section{KESIMPULAN}

Analisis kelimpahan Individu makrozoobenthos pada stasiun I tertinggi terdapat pada spesies Telescopium telescopium dengan nilai kelimpahan individu sebesar 33,333 $\left(\mathrm{Ind} / \mathrm{m}^{2}\right)$. Stasiun II dengan nilai tertinggi adalah spesies Episesarma yaitu $32,222\left(\mathrm{Ind} / \mathrm{m}^{2}\right)$, stasiun III nilai tertinggi terdapat spesies Telescopiun telescopium dan Episesarma dengan nilai yang sama yaitu $27,778\left(\mathrm{Ind} / \mathrm{m}^{2}\right)$. Sedangkan kelimpahan relatif pada stasiun I tertinggi adalah spesies Telescopium telescopium yaitu $(0,198 \%)$, stasiun II tertinggi spesies Episesarma $(0,200 \%)$. Kemudian nilai tertinggi pada stasiun III yaitu spesies Telescopium telescopium dan Episesarma dengan nilai persentase yang sama $(0,177$ \%). Hasil analisis Indeks ekologi pada tiga stasiun penelitian, untuk keanekaragaman jenis kategori sedang, indeks keseragaman kategori tinggi. Sedangkan indeks dominasi kotegori rendah (tidak ada spesies yang mendominasi).

\section{UCAPAN TERIMA KASIH}

Ucapan terima kasih sampaikan kepada semua pihak yang turut terlibat dalam penelitian ini, terutama para mahasiswa program studi IImu Kelautan Universitas Pasifik Morotai yang ikut terlibat dalam pengambilan data lapangan. 


\section{DAFTAR PUSTAKA}

Arief, A. 2003. Hutan Mangrove. Kanisius, Yogyakarta.

Barnes, R. D. 1987. Invertebrate Zoology, 5th Edition. W. B. Saunder Company. Philadelphia. London.

D. Alwi, K.Koroy, E.Laba 2019. Struktur Komunitas Ekosistem Mangrove di Desa Daruba Pantai Kabupaten Pulau Morotai. Jurnal Ilmiah Wahana Pendidikan Vol.5 No.4 e-ISSN: $2089-5364$ p-ISSN: 26228327. 33-46 p.

Effendi, I.J. 1993. Komposisi Jenis Dan Kelimpahan Makrozoobentos Pada Daerah PasangPantai Bervegetasi Mangrove Di Sekitar Teluk Mandar Desa Mirring Kecamatan Polewali Kabupaten Polmas. Fakultas Peternakan Universitas Hasanuddin. Ujung Pandang.

Fachrul, M. 2007. Metode Sampling Bioekologi. Bumi Aksara, Jakarta

Hardjosuwarno, S., 1990. Dasar-Dasar Ekologi Tumbuhan. Fakultas Biologi UGM. Yogyakarta.

Kariada, T.M., dan Andin, I., 2014. Peranan Mangrove sebagai Biofilter Pencemaran Air Wilayah Tambak Bandeng, Semarang. Jurnal Manusia dan Lingkungan, 21(2):188-194

Krebs, C.J. 1994. Ecology The Eksperimental Analysis Of Distribution And Abudance. Third edition. Haeper and Row Publisher. New york.

Nybakken, J.W. 1992. Biologi Laut Suatu Pendekatan Bilogis. Alih bahas oleh M. Eidman., Koesoebiono., D.G. Bengen., M. Hutomo., S. Sukardjo. $\quad$ PT.Gramedia Pustaka Utama. Jakarta, Indonesia.

Odum, E. P. 1993. Dasar-Dasar Ekologi. Edisi ketiga. Yogyakarta. Universitas Gadjah Mada Press.

Odum, E. P. 1971. Fundamental of Ekology. Third Edition, W.B. Saunders Company. Toronto Florida.

Ravichandran, S., W. Sylvester Frederick, S. Ajmal Khan dan T. Balasubramaniam. 2011. Diversity of Mangrove Crabs in South and Southeast Asia. Journal of Oceanography and Marine Environmental Systems 1(1): 01-07, 2011.

Smaldon, G. 1979. British Coastal Shrimps and Prawns.Synopses of the British Fauna (N.S.)

Soegianto, A. 1994. Ekologi Kuantitatif. Penerbit Usaha Nasional.Surabaya. 
Supriharyono 2009. Konservasi Ekosistem Sumberdaya Hayati dan Wilayah Pesisir dan Laut Tropis (Cetakan Pertama, Edisi Kedua). Yogyakarta: Pustaka Pelajar.

Widyastuti, A. 2011. Struktur Komunitas Makrozoobentos di Perairan Biak Selatan, Biak, Papua. Biak: UPT Loka Konservasi Biota Laut BiakLIPI.

Yulianto, A. 2006. Keanekaragaman Kepiting di Hutan Mangrove Desa Tungkal, Tanjung Jabung Barat, Jambi. Fakultas Perikanan. Bogor. 